\title{
Ю.Д. Шмидт
}

ФГАОУ ВО «Дальневосточный федеральный университет», Владивосток

\section{Л.А. Крохмаль}

ФГБУ ВО «Дальневосточный государственный аграрный университет», Благовещенск

\section{Н.В. Ивашина}

ФГАОУ ВО «Дальневосточный федеральный университет», Владивосток

\section{О финансировании государственных заданий вузам на выполнение научно-исследовательских работ}

\begin{abstract}
Аннотация. В статье рассматриваются вопросы результативности и финансирования научно-исследовательской деятельности высших учебных заведений страны. Исследуются эмпирические данные о результативности научно-исследовательской деятельности высших учебных заведений России. Предлагается ввести новую модель государственного финансирования научноисследовательской деятельности вузов страны. В рамках модели разработана методика расчета субсидий на базовое, гарантированное финансирование научной деятельности вузов, предназначенное для компенсации затрат на простое воспроизводство их научного потенциала. Сформирован и обоснован методами эконометрического моделирования интегральный показатель, который позволяет учесть влияние статистически значимых факторов на общий объем научно-исследовательских и опытно-конструкторских работ, выполненных вузом. Предложенный подход позволяет вычислять размеры гарантированного финансирования научной деятельности каждого вуза в плановом периоде при известном объеме финансовых ресурсов, выделенных на базовое финансирование научной деятельности вузов страны.
\end{abstract}

Ключевые слова: вузы, научно-исследовательская деятельность, финансирование, результативность, интегральный показатель, методика.

Классификация JEL: I230, I1220.

DOI: $10.31737 / 2221-2264-2021-50-2-6$

\section{1. Введение}

Интенсивное развитие национальных систем высшего образование серьезно влияет на формирование и развитие человеческого капитала и других инновационных ресурсов развитых стран. Процессы глобализации мировой экономики привели к формированию единого мирового образовательного пространства, которое способствует повышению спроса на знания и человеческий капитал, играющих важную роль в развитии национальных экономик. В этих условиях конкуренция национальных систем высшего образования является значимым элементом глобальной конкуренции национальных экономик и требует активного участия государства в поддержке и развитии национальной системы высшего образования. Формирование и развитие эффектив- 
ной системы государственной поддержки высшего образования страны требует научно обоснованных методологических и методических подходов, решения ряда сложных научных вопросов и привлечения значительных финансовых ресурсов.

Механизмы финансирования являются одними из самых мощных инструментов любого государства, используемых для управления национальными системами высшего образования. Важной сферой приложения таких механизмов является научно-исследовательская деятельность вузов, которая мощно влияет на повышение квалификации и развитие кадрового потенциала вузов, качество образовательного процесса и развитие научно-исследовательской работы студентов и их соответствующих профессиональных компетенций. Научно-исследовательская деятельность вузов может и должна вносить существенный вклад в инновационное развитие экономики страны и регионов.

\section{2. Государственное задание на проведение научных исследований}

Начиная с 2012 г. высшие учебные заведения, подведомственные Министерству науки и высшего образования РФ, получают финансирование на проведение научных исследований в форме государственного задания. Модель государственного задания в сфере науки была введена Постановлением Правительства Российской Федерации № 671 от 2 сентября 2010 г. Государственное задание было введено вместо тематического плана научных исследований государственных научных организаций и вузов.

В действующем законодательстве государственное задание позиционируется как документ, содержащий объем государственных услуг (работ), оказываемых учреждением. При этом ни один федеральный нормативно-правовой акт, включая федеральный закон «О науке и государственной научно-технической политике», не раскрывает требований к содержанию государственного задания в сфере науки. Ведомственный плюрализм в понимании государственного задания в сфере науки, его целей и содержательного направления продолжает сохраняться (Гусев и др., 2017).

Государственное задание в сфере науки как инструмент прямого бюджетного финансирования высших учебных заведений широко применяется во многих странах (Geuna, Martin, 2003). Анализ существующей практики организации финансирования научных исследований вузов показал, что в национальных системах высшего образования научные исследования чаще всего финансируются по специальным нормативам финансового обеспечения, которые реже включаются в норматив финансового обеспечения образовательных услуг. При әтом не оспаривается необходимость финансирования научных исследований университетов как отдельной функции, наравне с образова- 
тельными услугами (Frølich, Schmid, Rosa, 2010). Кроме того, государство обеспечивает равный доступ к финансовому обеспечению научной деятельности всем учреждениям, входящим в национальную систему высшего образования. Финансовое обеспечение вузовской науки обычно организуется таким образом, чтобы, как и при финансировании образовательной деятельности, можно было бы установить связь между показателями объема финансирования и качественными показателями результатов научной деятельности. Чаще всего финансирование научных исследований реализуется по простой и очень доступной для понимания схеме, которую к тому же можно легко трансформировать в зависимости от изменившихся условий развития сферы высшего образования. В результате финансовое обеспечение научной деятельности превращается в полноценный объект финансирования и входит в состав основного (гарантированного) объема финансового обеспечения деятельности учреждений высшего образования.

В качестве общей тенденции в мировой практике финансирования государственных заданий и распределения бюджетных средств на проведение научных работ можно выделить расширение принципов конкурсности (Вахштайн, Мешкова, Железов, 2005; Bolli, Somogyi, 2011).

Анализ показывает, что европейские страны широко используют нормативы финансового обеспечения научных исследований вузов в качестве обязательного элемента гарантированного финансирования учреждений национальных систем высшего образования. Пренебрежение этой тенденцией в настоящее время приводит в России к ухудшению качества не только образования, но и становится причиной снижения качественных характеристик академического сообщества, которое исторически являлось существенным преимуществом национальной системы высшего образования в России (Абанкина И., Абанкина Т., Филатова, 2016; Палочкина, 2018).

В документе «Положения по организации научных исследований, выполняемых подведомственными Министерству образования и науки РФ высшими учебными заведениями... ${ }^{1}$ указывалось, что бюджетное финансирование государственных заданий на выполнение НИР призвано способствовать достижению следующих целей:

- развитию научно-исследовательской и инновационной деятельности вузов;

- росту квалификации научных и научно-педагогических кадров.

Эти цели и в настоящее время остаются актуальными. Выделенное вузам финансирование должно стимулировать достижение поставленных целей. Следовательно, необходима система показателей, характеризующих научную деятельность вузов и степень достижения указанных целей. Для этого целесообразно использовать показатели, которые являются измеряемыми, объективными и значимыми.

\footnotetext{
${ }^{1}$ Положение по организации научных исследований, выполняемых подведомственными Министерству образования и науки Российской Федерации высшими учебными заведениями, в рамках государственного задания на оказание услуг (выполнение работ). Формирование государственных заданий высшим учебным заведениям на 2012 г. и на плановый период 2013 и 2014 г. в части проведения научно-исследовательских работ см.: http:www. dusp.ru/doc/pologenie_15112011.doc
} 


\section{3. Подходы к оценке результативности научной деятельности}

Для распределения финансовых ресурсов и развития научной деятельности вузов России необходимы инструменты для оценки научно-исследовательского потенциала и результатов научно-исследовательской деятельности. Все многообразие подходов к оценке результатов научной деятельности сводится к двум видам - экспертному и наукометрическому. Каждый подход имеет свои достоинства, но, к сожалению, также и недостатки (Абрамо, 2017; Калгин А., Калгина О., Лебедева, 2019; Чернова и др., 2017). Поэтому в мировой практике применяются одновременно оба подхода, но в различных странах в разных пропорциях. Как правило, учитываются следующие параметры оценки научной результативности вузов (Schmid, Graversen, 2018; Проктор, 2016; Dill, Soo, 2005; Гусев и др., 2017):

- объем финансирования научной деятельности организации за предыдущие периоды;

- численность обучающихся и выпускников по различным ступеням образования;

- наукометрические показатели: традиционные библиометрические показатели (количество публикаций, цитирований, импакт-фактор журналов), численность сотрудников, получивших степень доктора наук, количество патентов, объемы внебюджетного финансирования, уровень академической мобильности и интернациональности научных кадров;

- экспертный анализ.

Для обеспечения текущих потребностей вузов в воспроизводстве научного потенциала, повышении качества образовательных услуг и кадрового потенциала вузов предлагается ввести новую модель государственного финансирования научно-исследовательской деятельности вузов, состоящую из трех компонент, в соответствии с разработанной Л.А. Крохмаль концепцией государственной поддержки национальной системы высшего образования (Крохмаль, 2018а, 2018б). В первой компоненте предлагается базовое, гарантированное финансирование затрат на простое воспроизводство научного потенциала и научно-технологической инфраструктуры вуза, во второй - финансирование на конкурсной основе научных результатов и достижений вузов по широкому спектру направлений и наук, в третьей, целевой компоненте, предлагается стимулирование достижений вузами целей государственной политики.

Гарантированное финансирование, предназначенное для финансового обеспечения научно-исследовательской деятельности, обеспечивает текущую потребность вузов в источниках финансирования и стабильность их деятельности. Финансирование на конкурсной основе научных результатов и достижений вузов поощряет развитие научного потенциала и творческих коллективов на основе повыше- 
ния конкуренции и стимулирования достижения высших результатов, тогда как целевой компонент представляет собой отдельный элемент модели государственной поддержки и оказывает финансовую поддержку в достижении будущих целей, которые определяются на основе переговоров между отдельными вузами и учредителями (с учетом государственных целей и институциональных профилей).

\section{4. Методические основы исследования}

Формирование совокупности показателей, характеризующих результативность научной деятельности высших учебных заведений, уровень развития их научного потенциала и его әффективность, является сложной научной проблемой, которая требует дополнительного исследования значимости существующих и используемых показателей результативности научной деятельности в российской действительности. Для прогнозирования и расчета объективного объема средств для финансирования базового уровня научных исследований каждого вуза страны, с нашей точки зрения, можно использовать интегральный показатель, сформированный на основе эконометрического моделирования.

Для уточнения состава и коэффициентов интегрального показателя было построено регрессионное уравнение, в котором в качестве зависимой переменной выступает общий объем научно-исследовательских и опытно-конструкторских работ в стоимостном выражении, выполненных вузами России в течение определенного года (NIOKR). В настоящее время в России отсутствует сложившейся рынок прав на результаты НИОКР, поэтому стоимость НИОКР определяется не рыночными механизмами, а затратным методом или - на основе заданных нормативов. Этот показатель с определенной мерой условности характеризует величину научного потенциала вуза, который используется при выполнении научных исследований и опытно-конструкторских работ за отчетный период. Так как гарантированное базовое финансирование научной деятельности вуза предназначено для финансирования затрат на простое воспроизводство научного потенциала вуза и его научной инфраструктуры, то общий объем научно-исследовательских и опытно-конструкторских работ можно использовать, с нашей точки зрения, в качестве зависимой переменной регрессионного уравнения, на основе которого планируется формировать интегральный показатель для расчета базового финансирования научной деятельности вузов.

Анализ научной литературы об оценке результатов научной деятельности (Абрамо, 2017; Калгин А., Калгина О., Лебедева, 2019; Чернова и др., 2017; Schmid, Graversen, 2018; Проктор, 2016; Dill, Soo, $2005)$ позволил выделить совокупность факторов, влияющих на результативность научно-исследовательской деятельности. В этой совокупности многие показатели не имеют надежной статистической базы 
в российской практике, часть из них не используется в статистических наблюдениях в России. В этих условиях важное значение приобретают показатели, которые используются в мониторинге әффективности деятельности образовательных организаций высшего образования России, который проводит Министерство науки и высшего образования РФ². Этот мониторинг проводится с 2013 г. и содержит блок анализа научно-исследовательской деятельности вузов, в который входят 16 показателей, включая общий объем научно-исследовательских и опытно-конструкторских работ в стоимостном выражении.

Предварительный корреляционный и кросс-секционный анализ позволил выделить следующие показатели, влияющие на общий объем научно-исследовательских и опытно-конструкторских работ вузов в стоимостном выражении:

1) число публикаций организации, индексируемых в информационно-аналитической системе научного цитирования Scopus, в расчете на 100 научно-педагогических работников (НПР), единиц (Scopus);

2) удельный вес доходов от НИОКР в общих доходах образовательной организации, \% (DohodNIOKR);

3) общая численность профессорско-преподавательского состава (ППС) (без внешних совместителей и работающих по договорам гражданско-правового характера (ГПХ), человек (PPS);

4) общая численность научных работников (без внешних совместителей и работающих по договорам ГПХ), человек (NaukaRabotnik).

В составе вузов России достаточно много учреждений, в которых преобладают гуманитарные направления подготовки студентов. У таких вузов число публикаций, индексируемых в информационноаналитической системе научного цитирования Scopus, значительно превышает число публикаций, индексируемых в системе Web of Science, так как многие журналы гуманитарного направления, которые индексируются в базе Scopus, не индексируются в системе Web of Science, a многие технические и естественнонаучные журналы одновременно индексируются в системах Web of Science и Scopus. Поэтому показатель «Число публикаций организации, индексируемых в информационноаналитической системе научного цитирования Scopus, в расчете на 100 НПР» используется в качестве фактора при построении эконометрической модели.

Удельный вес доходов от НИОКР в общих доходах образовательной организации характеризует, с нашей точки зрения, величину и результативность использования научного потенциала вуза. В эконометрической модели предлагается использовать в качестве отдельных факторов общую численность ППС и общую численность научных работников в каждом вузе. Именно эти категории сотрудников вузов непосредственно осуществляют научную и конструкторскую деятель-

\footnotetext{
${ }^{2}$ Информационно-аналитические материалы по результатам проведения мониторинга эффективности деятельности образовательных организаций высшего образования. ГИВЦ Министерства образования и науки РФ; см. http://indicators.miccedu.ru/monitoring/2016/index.php?m=vpo
} 
ность. Однако во многих вузах число научных работников оказывается незначительным, а основную научно-исследовательскую работу выполняют преподаватели. Поэтому дополнительно планировалось исследовать вопрос, является ли число научных работников значимым фактором, влияющим на общий объем выполненных НИОКР.

Предварительный анализ показал, что общие объемы научноисследовательских и опытно-конструкторских работ различаются, как правило, для государственных и негосударственных вузов, а также зависят от профиля вуза. Поэтому в эконометрическую модель дополнительно вводим следующие факторы:

5) статус вуза (State - бинарная переменная, которая принимает значение, равное 1 , если вуз государственный, и 0 - в противном случае);

6) принадлежность к сфере искусства или спорта (ArtSport бинарная переменная, которая принимает значение, равное 1 , если вуз принадлежит к сфере искусства или спорта, и 0 - в противном случае).

Для построения моделей использовались данные по результатам научной деятельности вузов Российской Федерации за 2015-2018 гг. из базы мониторинга эффективности деятельности образовательных организаций высшего образования России Министерства науки и высшего образования РФ

Переменные NIOKR, PPS и NaukaRabotnik были предварительно прологарифмированы для приведения значений показателей к одному порядку, соответственно $\ln N I O K R, \ln P P S$ и $\ln$ NaukaRabotnik. Далее, чтобы избежать смещения коэффициентов регрессионного уравнения и включения в модель дублирующих друг друга переменных, была проведена проверка факторов на мультиколлинеарность. Для каждого фактора был рассчитан коэффициент вздутия дисперсии (VIF), значения которого показали отсутствие мультиколлинеарности между переменными.

Регрессии на панельных данных были построены для 550 вузов РФ для периода 2015-2018 гг. (четыре периода наблюдений), а также после удаления из выборки аномальных наблюдений (вузы, для которых объемы НИОКР существенно выше среднего уровня (МГУ им. М.В. Ломоносова и МГТУ им. Н.Э. Баумана)).

В настоящем исследовании использовалась спецификация модели со случайными эффектами (1), поскольку размер общего объема научно-исследовательских и опытно-конструкторских работ, выполненных вузом, практически не изменился за небольшое число периодов наблюдений, а большая часть изменчивости регрессоров отражается не во времени, а внутри кросс-секций. В работе (Wooldridge, 2002) отмечается, что в данном случае оценки коэффициентов регрессоров в модели с фиксированными эффектами могут быть неэффективными, т.е. не обладать наименьшей дисперсией в классе линейных несмещен- 
ных оценок. Модель со случайными индивидуальными эффектами $(R E)$ оценивалась обобщенным методом наименьших квадратов (GLS),

$$
\begin{aligned}
& \ln \text { NIOKR }_{i t}=\alpha+\beta \text { Scopus }_{i t}+\gamma \text { DohodNIOKR } \delta \ln \text { PPS }+ \\
& +\lambda \ln \text { NaukaRabotnik }_{i t}+\mu \text { State }_{i}+\varphi \text { ArtSport }_{i}+\varepsilon_{i t},
\end{aligned}
$$

где $\varepsilon_{i t}=\omega_{i}+u_{i t}, \omega_{i}-$ случайный индивидуальный эффект вуза $i$, который является частью случайной ошибки и отражает влияние пропущенных (ненаблюдаемых) переменных, характеризующих индивидуальные особенности исследуемого объекта (вуза).

Результаты оценивания модели (1) на панельных данных приведены в табл. 1 (столбцы 1 и 3). Для учета разницы между государственными и негосударственными вузами, а также между вузами культуры и спорта и остальными вузами не только в свободных членах, а также в коэффициентах регрессии при значимых факторах, в исходную спецификацию модели были добавлены попарные произведения бинарных переменных State и ArtSport с остальными факторами. В столбцах 2 и 4

Таблица

\begin{tabular}{|c|c|c|c|c|}
\hline \multirow[t]{2}{*}{ Переменные } & \multicolumn{2}{|c|}{ Все вузы } & \multicolumn{2}{|c|}{$\begin{array}{c}\text { Вузы без МГУ } \\
\text { им. М.В. Ломо- } \\
\text { носова и МГТУ } \\
\text { им. Н.Э. Баумана }\end{array}$} \\
\hline & 1 & 2 & 3 & 4 \\
\hline $\begin{array}{l}\text { Число публикаций, индексируемых в Scopus, в рас- } \\
\text { чете на } 100 \text { НПР, ед. (Scopus) }\end{array}$ & $\begin{array}{c}0,0026^{* * * *} \\
(0,000)\end{array}$ & $\begin{array}{c}0,0022^{* * * *} \\
(0,001)\end{array}$ & $\begin{array}{c}0,0026^{* * * *} \\
(0,000)\end{array}$ & $\begin{array}{c}0,0022^{* * * *} \\
(0,001)\end{array}$ \\
\hline $\begin{array}{l}\text { Удельный вес доходов от НИОКР в общих доходах } \\
\text { образовательной организации, \% (DohodNIOKR) }\end{array}$ & $\begin{array}{c}0,0584^{* * *} \\
(0,002)\end{array}$ & $\begin{array}{c}0,0323^{* * *} \\
(0,003)\end{array}$ & $\begin{array}{c}0,0582^{* * *} \\
(0,002)\end{array}$ & $\begin{array}{c}0,0323^{* * *} \\
(0,003)\end{array}$ \\
\hline $\begin{array}{l}\text { Логарифм общей численности ППС, человек } \\
(\ln P P S) ;\end{array}$ & $\begin{array}{c}0,7937^{* *} \\
(0,028) \\
\end{array}$ & $\begin{array}{c}0,6767^{* * * *} \\
(0,053)\end{array}$ & $\begin{array}{l}0,7913^{* *} \\
(0,028) \\
\end{array}$ & $\begin{array}{c}0,6769^{* * *} \\
(0,054)\end{array}$ \\
\hline $\begin{array}{l}\text { Логарифм общей численности научных работни- } \\
\text { ков, человек (lnNaukaRabotnik) }\end{array}$ & $\begin{array}{c}0,1909^{* * *} \\
(0,017)\end{array}$ & $\begin{array}{c}0,1639^{* * *} \\
(0,017)\end{array}$ & $\begin{array}{c}0,1893^{* * *} \\
(0,017)\end{array}$ & $\begin{array}{c}0,1630^{* *} \\
(0,017)\end{array}$ \\
\hline Статус вуза (State) & $\begin{array}{c}0,218^{*} \\
(0,082)\end{array}$ & $\begin{array}{c}-0,6239 \\
(0,268)\end{array}$ & $\begin{array}{l}0,2239^{*} \\
(0,082)\end{array}$ & $\begin{array}{c}-0,6112 \\
(0,269)\end{array}$ \\
\hline $\begin{array}{l}\text { Принадлежность к сфере искусства или спорта } \\
\text { (ArtSport) }\end{array}$ & $\begin{array}{l}-0,255^{*} \\
(0,075) \\
\end{array}$ & $\begin{array}{c}-0,4920^{*} \\
(0,092)\end{array}$ & $\begin{array}{c}-0,259^{*} \\
(0,075) \\
\end{array}$ & $\begin{array}{c}-0,4951^{*} \\
(0,092)\end{array}$ \\
\hline State $\times$ DohodNIOKR & & $\begin{array}{c}0,0388^{* * * *} \\
(0,004)\end{array}$ & & $\begin{array}{c}0,0387^{* * * *} \\
(0,004)\end{array}$ \\
\hline State $\times \ln P P S$ & & $\begin{array}{l}0,1415^{*} \\
(0,061) \\
\end{array}$ & & $\begin{array}{l}0,1394^{*} \\
(0,061) \\
\end{array}$ \\
\hline ArtSport $\times$ DohodNIOKR & & $\begin{array}{c}0,0483^{* * * * *} \\
(0,010)\end{array}$ & & $\begin{array}{c}0,0484^{* * * *} \\
(0,010)\end{array}$ \\
\hline Const & 5,1168 & 5,7655 & 5,1254 & 5,7842 \\
\hline $\mathrm{R}^{2}$-overall & 0,84 & 0,85 & 0,84 & 0,85 \\
\hline Число наблюдений & 2200 & 2200 & 2192 & 2192 \\
\hline
\end{tabular}

Результаты оценивания панельных данных

Примечание. Зависимая переменная - логарифм общего объема научно-исследовательских и опытно-конструкторских работ, выполненных вузом в отчетном году, тыс. руб. (ln NIOKR). Символами «"», «"*», «*** » отмечены оценки, значимые на уровне 10,5 и $1 \%$ соответственно. В круглых скобках приведены значения стандартных ошибок оценок коэффициентов. 
представлены результаты оценки полученной модели только со значимыми произведениями переменных.

Все коэффициенты при факторных переменных значимы, уравнения регрессий значимы на любом уровне значимости. Удаление выбросов по переменной $\ln N I O K R$ несущественно повлияли на оценки коэффициентов.

Оценки коэффициентов при факторах в регрессионном уравнении (1) значимы и положительны, за исключением переменной ArtSport. Это говорит о том, что все выделенные факторы положительно влияют на общий объем научно-исследовательских и опытноконструкторских работ в стоимостном выражении. В государственных вузах объемы научно-исследовательских и опытно-конструкторских работ существенно выше, чем в негосударственных, а в вузах искусства и спорта - значительно ниже, чем в других вузах.

Если учитывать попарные произведения бинарных переменных State и ArtSport с остальными факторами, оценки коэффициентов при которых оказались значимыми (см. табл. 1), регрессионное уравнение примет вид:

$$
\begin{gathered}
\ln \text { NIOKR }=\beta_{0}+\beta_{1} \text { Scopus }+\beta_{2} \text { DohodNIOKR }+\beta_{3} \ln P P S+ \\
+\beta_{4} \ln \text { NaukaRabotnik }+\beta_{5} \text { State }+\beta_{6} \text { ArtSport }+\beta_{7} \text { DohodNIOKR } \times \text { State }+ \\
+\beta_{8} \text { DohodNIOKR } \times \text { ArtSport }+\beta_{9} \ln \text { PPS } \times \text { State } .
\end{gathered}
$$

Рассмотрим все возможные исходы, учитывая значения бинарных переменных и спецификацию модели (2), - столбец 2 табл. 1.

Если State $=1$, а ArtSport $=0$, т.е. для государственных вузов, отличных от вузов культуры и спорта, регрессионное уравнение выглядит следующим образом:

$$
\begin{aligned}
& \ln N I O K R=5,142+0,022 \text { Scopus }+0,711 \text { DohodNIOKR+ } \\
& +0,818 \ln P P S+0,164 \ln \text { NaukaRabotnik. }
\end{aligned}
$$

Если State $=0$, a ArtSport $=0$, т.е. для негосударственных вузов, отличных от вузов культуры и спорта, регрессионное уравнение выглядит следующим образом:

$$
\begin{aligned}
& \ln \text { NIOKR }=5,766+0,022 \text { Scopus }+0,323 \text { DohodNIOKR+ } \\
& +0,677 \ln P P S+0,164 \ln \text { NaukaRabotnik. }
\end{aligned}
$$

Если State $=1$, а ArtSport $=1$, т.е. для государственных вузов сферы культуры и спорта, регрессионное уравнение выглядит следующим образом:

$$
\begin{aligned}
& \ln \text { NIOKR }=4,65+0,022 \text { Scopus }+1,194 \text { DohodNIOKR }+ \\
& +0,818 \ln \text { PPS + 0,164 } \ln \text { NaukaRabotnik. }
\end{aligned}
$$

Если State $=0$, а ArtSport $=1$, т.е. для негосударственных вузов сферы культуры и спорта, регрессионное уравнение выглядит следующим образом: 
$\ln$ NIOKR $=5,274+0,022$ Scopus $+0,806$ DohodNIOKR + $+0,677 \ln P P S+0,164 \ln$ NaukaRabotnik.

\section{5. Результаты расчетов}

Для вычислений объема финансирования научной деятельности каждого вуза используем регрессионные уравнения (3)-(6) для соответствующих вузов. Применяя потенцирование к обеим частям регрессионных уравнений, получим общий объем научно-исследовательских и опытно-конструкторских работ, выполненных вузом в отчетном году (NIOKR).

1. Для государственных вузов, отличных от вузов культуры и спорта:

$$
\begin{aligned}
& \text { NIOKR }=\mathrm{e}^{5,142}\left(\mathrm{e}^{0,022}\right)^{X_{1}}\left(\mathrm{e}^{0,711}\right)^{X_{2}}\left(X_{3}\right)^{0,818}\left(X_{4}\right)^{0,164}= \\
& =171,06(1,022)^{X_{1}}(2,036)^{X_{2}}\left(X_{3}\right)^{0,818}\left(X_{4}\right)^{0,164} .
\end{aligned}
$$

2. Для негосударственных вузов, отличных от вузов культуры и спорта:

$$
\begin{aligned}
& \text { NIOKR }=\mathrm{e}^{5,766}\left(\mathrm{e}^{0,022}\right)^{X_{1}}\left(\mathrm{e}^{0,323}\right)^{X_{2}}\left(X_{3}\right)^{0,677}\left(X_{4}\right)^{0,164}= \\
& =319,26(1,022)^{X_{1}}(1,381)^{X_{2}}\left(X_{3}\right)^{0,677}\left(X_{4}\right)^{0,164} .
\end{aligned}
$$

3. Для государственных вузов сферы культуры и спорта:

$$
\begin{aligned}
& \text { NIOKR }=\mathrm{e}^{4,65}\left(\mathrm{e}^{0,022}\right)^{X_{1}}\left(\mathrm{e}^{1,194}\right)^{X_{2}}\left(X_{3}\right)^{0,818}\left(X_{4}\right)^{0,164}= \\
& =104,59(1,022)^{X_{1}}(3,30)^{X_{2}}\left(X_{3}\right)^{0,818}\left(X_{4}\right)^{0,164} .
\end{aligned}
$$

4. Для негосударственных вузов сферы культуры и спорта:

$$
\begin{aligned}
& \text { NIOKR }=\mathrm{e}^{5,274}\left(\mathrm{e}^{0,022}\right)^{X_{1}}\left(\mathrm{e}^{0,806}\right)^{X_{2}}\left(X_{3}\right)^{0,677}\left(X_{4}\right)^{0,164}= \\
& =195,195(1,022)^{X_{1}}(2,239)^{X_{2}}\left(X_{3}\right)^{0,677}\left(X_{4}\right)^{0,164},
\end{aligned}
$$

где $X_{1}$ - число публикаций организации, индексируемых в информационно-аналитической системе научного цитирования Scopus, в расчете на 100 НПР (Scopus); $X_{2}$ - удельный вес доходов от НИОКРв общих доходах образовательной организации (DohodNIOKR); $X_{3}-$ общая численность ППС (без внешних совместителей и работающих по договорам ГПХ) (PPS); $X_{4}$ - общая численность научных работников (без внешних совместителей и работающих по договорам ГПХ) (NaukaRabotnik).

Для вычисления объемов финансирования научной деятельности по вузам будем использовать функции $f_{i}\left(X_{1}, \ldots, X_{4}\right)$, вычисленные по формулам:

1) государственные вузы, отличные от вузов культуры и спорта:

$$
f_{1}\left(X_{1}, X_{2}, X_{3}, X_{4}\right)=171,06(1,022)^{X_{1}}(2,036)^{X_{2}}\left(X_{3}\right)^{0,818}\left(X_{4}\right)^{0,164}
$$

2) негосударственные вузы, отличные от вузов культуры и спорта:

$$
f_{2}\left(X_{1}, X_{2}, X_{3}, X_{4}\right)=319,26(1,022)^{X_{1}}(1,381)^{X_{2}}\left(X_{3}\right)^{0,677}\left(X_{4}\right)^{0,164} \text {; }
$$


3) государственные вузы сферы культуры и спорта:

$$
f_{3}\left(X_{1}, X_{2}, X_{3}, X_{4}\right)=104,59(1,022)^{X_{1}}(3,30)^{X_{2}}\left(X_{3}\right)^{0,818}\left(X_{4}\right)^{0,164} ;
$$

4) негосударственные вузы сферы культуры и спорта:

$$
f_{4}\left(X_{1}, X_{2}, X_{3}, X_{4}\right)=195,195(1,022)^{X_{1}}(2,239)^{X_{2}}\left(X_{3}\right)^{0,677}\left(X_{4}\right)^{0,164} \text {; }
$$

где $X_{1}-$ прогнозируемое число публикаций вуза на плановый период, индексируемых в информационно-аналитической системе научного цитирования Scopus, в расчете на $100 \mathrm{HПР;} X_{2}$ - прогнозируемый удельный вес доходов вуза от НИОКР в общих доходах на плановый период; $X_{3}-$ прогнозируемая общая численность ППС вуза на плановый период; $X_{4}$ - прогнозируемая общая численность научных работников (без внешних совместителей и работающих по договорам ГПХ) вуза на плановый период.

По всем вузам вычисляем оценку $R$ общего объема научно-исследовательских и опытно-конструкторских работ, выполненных вузами в плановом периоде, в стоимостном выражении по формуле:

$$
R=\sum_{i=1}^{4} \sum_{j=1}^{N} f_{i}\left(X_{j 1}, X_{j 2}, X_{j 3}, X_{j 4}\right),
$$

где $N$ - число вузов типа $i ; X_{j 1}$ - прогнозируемое число публикаций вуза $j$ на плановый период, индексируемых в информационно-аналитической системе научного цитирования Scopus, в расчете на 100 HПР; $X_{j 2}-$ прогнозируемый удельный вес доходов вуза $j$ от НИОКР в общих доходах на плановый период; $X_{j 3}-$ прогнозируемая общая численность ППС вуза $j$ на плановый период; $X_{j 4}-$ прогнозируемая общая численность научных работников (без внешних совместителей и работающих по договорам ГПХ) вуза $j$ на плановый период.

Если $V$ - общий объем финансирования научной деятельности всех вузов на плановый период, то объем финансирования $V_{i}$ вуза $i$ рассчитываем по формуле

$$
V_{i}=f\left(X_{i 1}, \ldots, X_{i 4}\right) V / R,
$$

где $f\left(X_{i 1}, \ldots, X_{i 4}\right)$ вычисляется по формулам (7)-(10) в зависимости от типа вуза.

В настоящее время в России финансирование научных исследований высших учебных заведений в рамках государственного задания производит не один, а несколько главных распорядителей бюджетных средств. Учитывая этот факт, формулы (11)-(12) легко преобразовать для расчета величины финансирования базовой части государственного задания вузам на выполнение научно-исследовательских работ для одного конкретного главного распорядителя бюджетных средств. Покажем это на примере Министерства сельского хозяйства РФ, в ведении которого находятся 54 аграрных высших учебных заведения. В 2018 г. на финансирование базовой части государственного задания для выполнения научно-исследовательских работ вузам сель- 
скохозяйственного профиля Минсельхоз РФ выделил 204900 тыс. руб. Следовательно, в наших обозначениях для этих вузов $V=204900$ тыс. руб. Вычисляем для каждого аграрного вуза на 2018 г. значения функции $f_{i}\left(X_{1}, \ldots, X_{4}\right)$ по формуле $(7)$, так как все рассматриваемые вузы государственные и их профиль не связан с культурой и спортом. В качестве прогнозируемых значений переменных $X_{1}, \ldots, X_{4}$ используем для каждого вуза значения соответствующих переменных на конец 2017 г. по данным мониторинга эффективности деятельности образовательных организаций высшего образования России функций $f_{i}\left(X_{1}, \ldots, X_{4}\right)$ для аграрных вузов $R=\sum_{j=1}^{54} f_{1}\left(X_{j 1}, \ldots, X_{j 4}\right)=302$. Вычисляем объем финансирования базовой части государственного задания на выполнение научно-исследовательских работ $V_{i}$ аграрного вуза $i$ по формуле

$$
V_{i}=R_{i} V / R,
$$

где $R_{i}$ - значение функции $f_{1}\left(X_{1}, \ldots, X_{4}\right)$ для аграрного вуза $i ; R-$ общая сумма значений функций $f_{i}\left(X_{1}, \ldots, X_{4}\right)$ для аграрных вузов; $V$ - общий объем финансирования базовой части государственного задания на выполнение научно-исследовательских работ вузам сельскохозяйственного профиля Министерством сельского хозяйства Российской Федерации.

В табл. 2 представлены данные об объемах финансирования базовой части государственного задания на выполнение научно-исследовательских работ в порядке их убывания, выделенные Минсельхозом РФ в 2018 г. для 20 аграрных вузов, и суммы финансирования базовой части государственного задания, вычисленные по предлагаемой методике для этих вузов.

Сравнительный анализ объемов финансирования базовой части государственного задания на выполнение научно-исследовательских работ по аграрным вузам, выделенных в 2018 г. Минсельхозом РФ и вычисленных по предлагаемой методике, показывает существенную разницу между ними, даже на небольшом общем объеме финансирования. Например, Смоленской государственной сельскохозяйственной академии в 2018 г. было выделено 10,5 млн руб. по государственному заданию на научные исследования. Это - третья по величине сумма, выделенная на финансирование базовой части государственного задания на выполнение научно-исследовательских работ для аграрного вуза, а по научному потенциалу и объемам НИОКР, выполненным в 2017 г., этот вуз занимает последнее, 54 место среди аграрных вузов. Понятно, что государство, активно используя механизмы субсидирования вузовской науки, продолжает поддерживать прежде всего ресурсоемкие механизмы и проекты, требующие больших затрат, но такие факты не добавляют прозрачности механизмам распределения ограниченных финансовых ресурсов. Следует отметить, что финансирование базовой части государственного задания на выполнение научно-исследователь-

\footnotetext{
${ }^{3}$ Информационно-аналитические материалы по результатам проведения мониторинга эффективности деятельности образовательных организаций высшего образования. ГИВЦ Министерства образования и науки РФ. http://indicators.miccedu.ru/monitoring/2016/index.php?m=vpo
} 


\section{таблица 2}

Объемы финансирования государственного задания на выполнение научноисследовательских работ по некоторым аграрным вузам России в 2018 г.

\begin{tabular}{|c|c|c|c|c|c|c|c|}
\hline 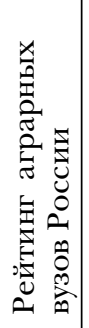 & Вуз & 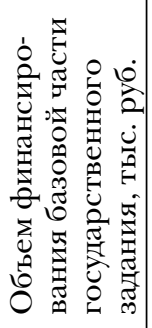 & 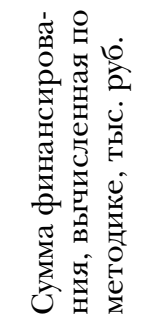 & 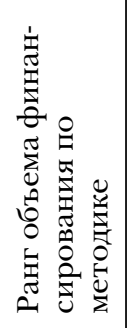 & 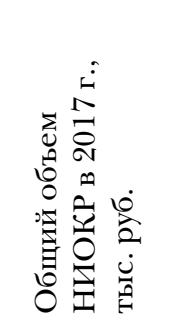 & 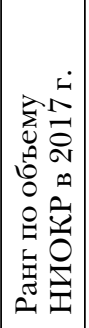 & 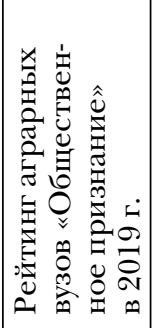 \\
\hline 1 & $\begin{array}{l}\text { ФГБОУ ВО «Ставропольский } \\
\text { ГАУ» }\end{array}$ & 13700 & 7662,2 & 4 & 187036,8 & 2 & 1 \\
\hline 2 & $\begin{array}{l}\text { ФГБОУ ВО «РГАУ - МСХА } \\
\text { им. К.А. Тимирязева» }\end{array}$ & 12000 & 17743,5 & 1 & 330942,4 & 1 & 3 \\
\hline 3 & ФГБОУ ВО «Смоленская ГСХА» & 10500 & 1136,0 & 54 & 6816 & 54 & 51 \\
\hline 4 & ФГБОУ ВО «Кубанский ГАУ» & 8800 & 11992,5 & 2 & 154773,6 & 4 & 2 \\
\hline 5 & ФГБОУ ВО «Рязанский ГАТУ» & 8400 & 2359,4 & 36 & 35583,3 & 22 & 14 \\
\hline 6 & ФГБОУ ВО «Донской ГАУ» & 7590 & 2932,2 & 29 & 33067 & 25 & 7 \\
\hline 7 & $\begin{array}{l}\text { ФГБОУ ВО «Оренбургский } \\
\text { ГАУ» }\end{array}$ & 7000 & 6498,5 & 6 & 71725,6 & 9 & 20 \\
\hline 8 & $\begin{array}{l}\text { ФГБОУ ВО «Госуниверситет по } \\
\text { землеустройству» }\end{array}$ & 6300 & 3053,2 & 28 & 50164 & 15 & 22 \\
\hline 9 & ФГБОУ ВО «Саратовский ГАУ» & 6000 & 6823,6 & 5 & 144625 & 5 & 5 \\
\hline 10 & ФГБОУ ВО «Орловский ГАУ» & 5500 & 4675,6 & 11 & 91559,9 & 7 & 9 \\
\hline 11 & $\begin{array}{l}\text { ФГБОУ ВО «Кабардино-Балкар- } \\
\text { ский ГАУ» }\end{array}$ & 4650 & 4451,1 & 17 & 21975,8 & 38 & 28 \\
\hline 12 & ФГБОУ ВО «Мичуринский ГАУ» & 4500 & 4680,4 & 10 & 85789,2 & 8 & 27 \\
\hline 13 & $\begin{array}{l}\text { ФГБОУ ВО «Волгоградский } \\
\text { ГАУ» }\end{array}$ & 4200 & 7826,6 & 3 & 117262,3 & 6 & 11 \\
\hline 14 & $\begin{array}{l}\text { ФГБОУ ВО «Новосибирский } \\
\text { ГАУ» }\end{array}$ & 4200 & 4606,5 & 14 & 54391,8 & 12 & 19 \\
\hline 15 & ФГБОУ ВО «Брянский ГАУ» & 4200 & 3242,2 & 25 & 40664 & 19 & 17 \\
\hline 16 & ФГБОУ ВО «Башкирский ГАУ» & 3900 & 5582,6 & 8 & 53232,4 & 13 & 4 \\
\hline 17 & $\begin{array}{l}\text { ФГБОУ ВО «Санкт- } \\
\text { Петербургский ГАУ» }\end{array}$ & 3800 & 4659,2 & 13 & 60947,3 & 10 & 15 \\
\hline 18 & $\begin{array}{l}\text { ФГБОУ ВО «Московская } \\
\text { ГАВМиБ» }\end{array}$ & 3800 & 3301,2 & 22 & 51758,8 & 14 & 23 \\
\hline 19 & $\begin{array}{l}\text { ФГБОУ ВО «Российский госу- } \\
\text { дарственный аграрный заочный } \\
\text { университет» }\end{array}$ & 3600 & 2093,8 & 39 & 9059,5 & 50 & 38 \\
\hline 20 & ФГБОУ ВО «Омский ГАУ» & 3500 & 4479,3 & 15 & 48480 & 17 & 18 \\
\hline & Всего & 201904,9 & 201904,9 & - & 2632857,5 & - & - \\
\hline
\end{tabular}

Источник: фактический объем финансирования - План финансово-хозяйственной деятельности на 2018 год. Раздел II, строка 10 (код строки 122), столбец 5 (см. Сайты аграрных вузов); расчетные значения - рассчитано авторами.

* Univer.Expert. Академический критик (см. https:/ / univer.expert/akademicheskiye-reytingi/rejting-agrarnyh-vuzov-2019/). 
ских работ вузам, согласно разработанной методике, предназначено для простого воспроизводства научного потенциала вузов. Поэтому общая сумма выделяемых в настоящее время на базовую часть государственного задания на выполнение научно-исследовательских работ вузам Минсельхозом РФ, как и другими главными распорядителями бюджетных средств, явно недостаточна для реализации этих функций.

Вычисление объемов финансирования базовой части государственного задания на выполнение научно-исследовательских работ в разработанной методике основано на открытых данных мониторинга эффективности деятельности образовательных организаций высшего образования России, которые характеризуют актуальный научно-исследовательский потенциал вузов России. С нашей точки зрения, для развития механизмов финансирования базовой части государственного задания и увеличения их прозрачности необходимо использовать информационные системы мониторинга әффективности деятельности вузов России и учета научно-исследовательских, опытно-конструкторских и технологических работ гражданского назначения ЕГИСУ НИОКТР (www.rosrid.ru).

В табл. 2 представлены данные по рейтингу аграрных вузов России «Общественное признание», который характеризует научный кадровый потенциал вузов России на основе вычисления общих сумм нормированных значений индексов Хирша сотрудников вузов в Российском индексе научного цитирования (РИНЦ). С нашей точки зрения, этот рейтинг не в полной мере отражает не только научный потенциал вузов, но и их научный кадровый потенциал. Ориентация только на РИНЦ не соответствует современным тенденциям развития отечественной науки.

Использование предложенной методики расчета объема финансирования базовой части государственного задания на выполнение научно-исследовательских работ вузам позволяет учесть вклад статистически значимых факторов в формирование результатов научной деятельности вузов и величину их использования в плановом периоде на основе уже достигнутых в отчетном периоде результатов.

\section{6. Выводы}

Инструмент государственной научно-технической политики государственное задание вузам на выполнение научно-исследовательских работ распределяет ограниченные бюджетные финансовые ресурсы между высшими учебными заведениями страны и имеет ряд существенных недостатков. Одним из таких недостатков является сложность определения необходимых объемов финансирования для конкретных вузов и реализуемых научных проектов. Разработанные в данном исследовании инструментарий и алгоритм расчета объема финансирования научно-исследовательской деятельности высших учебных заведений ориентированы на базовый уровень, на гарантиро- 
ванное финансирование, предназначенное для простого воспроизводства научного потенциала и научно-технологической инфраструктуры вузов. Реализация такого подхода может быть успешной альтернативой государственному заданию вузам на научные исследования в части базового гарантированного финансирования научно-исследовательской деятельности вуза.

При этом речь идет только о базовом уровне. Финансирование расширенного воспроизводства научного потенциала вузов и развитие их научно-исследовательской деятельности, с нашей точки зрения, должно происходить на конкурсной основе, с учетом результативности и эффективности научно-исследовательской деятельности вузов. Это способствует совершенствованию механизмов управления научными исследованиями путем повышения их прозрачности и стимулирует конкуренцию между вузами и научными коллективами, усиливает внутреннюю мотивацию членов академического сообщества.

\section{ЛИТЕРАТУРA / REFERENCES}

Абанкина И.В., Абанкина Т.В., Филатова Л.М. (2016). Ловушки дифференциации в финансировании российских вузов // Ажтуальные проблемы экономики и права. T. 10. № 2. C. 38-58. [Abankina I.V., Abankina T.V., Filatova L.M. (2016). The pitfalls of differentiation in the financing of Russian universities. Actual Problems of Economics and Law, 10, 2, 38-58 (in Russian).]

Абрамо Д. (2017). Библиометрическая оценка результативности научно-исследовательской работы: к чему мы пришли? / / Вопросы образования. № 1. C. 112-127. [Abramo D. (2017). Bibliometric assessment of the effectiveness of research work: what have we come to? Educational Studies. Moscow, 1, 112127 (in Russian).]

Вахштайн В.С., Мешкова Т.А., Железов Б.В. (2005). Основные тенденции государственной политики в сфере высшего образования в странах ОЭСР / / Вопросы образования. № 2. C. 32-46. [Vakhshtain V.S., Meshkova T.A., Zhelezov B.V. (2005). Key trends in public policy in higher education in the OECD countries. Educational Studies. Moscow, 2, 32-46 (in Russian).]

Гусев А., Ладный А., Белоклоков Е., Юревич М. (2017). О государственном задании в сфере науки / / Общество и экономика. № 11. C. 5-23. [Gusev A., Ladnyi A., Beloklokov E., Jurevich M. (2017). About the state task in the field of science. Society and Economics, 11, 5-23 (in Russian).]

Калгин А.С., Калгина О.В., Лебедева А.А. (2019). Оценка публикационной активности как способ измерения результативности труда ученых и ее связь с мотивацией / / Вопросы образования. № 1. С. 44-86. [Kalgin A.S., Kalgina O.V., Lebedeva A.A. (2019). Evaluation of publication activity as a way to measure the effectiveness of scientists ' work and its relation to motivation. Educational Studies. Moscow, 1, 44-86 (in Russian).]

Крохмаль Л.А. (2018a). Совершенствование модели государственной поддержки услуг высшего образования в России // Проблемы экономики и юридической практики. № 5. C. 72-79. [Krokhmal L.A. (2018a). The features of legal 
regulation of the infrastructure mortgage in the Russian Federation. Economic Problems and Legal Practice, 5, 72-79 (in Russian).]

Крохмаль Л.А. (2018б). Трансформация моделей государственной поддержки высшего образования в контексте концепции экономической социодинамики // Экономика и менеджмент систем управления. № 4.1(30). С. 133-137. [Krokhmal L.A. (2018b). Transformation of models of state support of higher education in the context of the concept of economic sociodynamics. Economics and Management of Management Systems, 4.1 (30), 133-137 (in Russian).]

Палочкина В.В. (2018). Развитие механизмов финансирования высшего образования как условия повышения качества образовательных услуг // Вестник Института экономики Российской академии наук. № 2. С. 188-197. [Palochkina V.V. (2018). Development of mechanisms of financing higher education as a condition for improving the quality of educational services. Bulletin of IE RAS, 2, 188-197 (in Russian).]

Проктор Д. (2016). Изменение ландшафта исследований в международном образовании // Международное высшее образование. № 84. C. 24-25. [Proktor D. (2016). Changing the research landscape in international education. International Higher Education HSE, 84, 24-25 (in Russian).]

Чернова Е.Г., Ахобадзе Т.Д., Малова А.С., Салтан А.А. (2017). Модели финансирования образования и эффективность деятельности университетов / / Вопросы образования. № 3. С. 37-82. [Chernova E.G., Akhobadze T.D., Malova A.S., Saltan A.A. (2017). Higher education funding models and institutional effectiveness. Educational Studies. Moscow, 3, 37-82 (in Russian).]

Bolli T., Somogyi F. (2011). Do competitively acquired funds induce universities to increase productivity? Research Policy, 40, 1, 136-147.

Dill D.D., Soo M. (2005). Academic quality, league tables, and public policy: A crossnational analysis of university ranking systems. Higher Education, 49, 4, 495-533.

Frølich N., Schmid E.K., Rosa M.J. (2010). Funding systems for higher education and their impacts on institutional strategies and academia. International Journal of Educational Management, 24 (1), 7-21.

Geuna A., Martin B.R. (2003). University research evaluation and funding: An international comparison. Minerva, 41, 4, 277-304.

Schmid E.K., Graversen E.K. (2018). Persistent factors facilitating excellence in research environments. Higher Education, 75, 2, 341-363.

Wooldridge J.M. (2002). Econometric analysis of cross section and panel data. London: The MIT Press Cambridge.

Поступила в редакиию 27.05.2020

Received 27.05.2020 


\title{
Yu.D. Shmidt
}

Far Eastern Federal University, Vladivostok, Russia

\section{L.A. Krokhmal}

Far Eastern State Agrarian University, Blagoveshchensk, Russia

\author{
N.V. Ivashina
}

Far Eastern Federal University, Vladivostok, Russia

\section{On financing the state assignments to higher education institutions to perform research and development projects}

\begin{abstract}
The paper presents the issues of higher education institutions research activities efficiency and financing. Empirical data on the Russian higher education institutions research activities efficiency have been investigated. A new model for higher education institutions research activities public financing has been suggested. The model developed a methodology for calculating subsidies for basic, guaranteed funding of scientific activities of universities, designed to compensate for the cost of simple reproduction of their scientific potential. The integral index, which allows accounting the influence of statistically significant factors on the total amount of research and development work performed by the University, is formed and justified by methods of econometric modeling. The proposed approach allows us to calculate the amount of guaranteed funding for the scientific activities of each university in the planning period with a known amount of financial resources allocated for the basic financing of scientific activities of universities in the country.
\end{abstract}

Keywords: higher education institutions, research activities, financing, efficiency, integrated index, technique.

JEL Classification: I230, I1220.

DOI: 10.31737 / 2221-2264-2021-50-2-6 